\title{
Influence of BK7 Substrate Solarization on the Performance of Hafnia and Silica Multilayer Mirrors
}

C. J. Stolz, J. A. Menapace, F. Y. Génin, P. R. Ehrmann, P. E. Miller and G. T. Rogowski

Boulder Damage Symposium XXXIV

Annual Symposium on Optical Materials for High Power Lasers Boulder, Colorado

September 16-20, 2002

U.S. Department of Energy

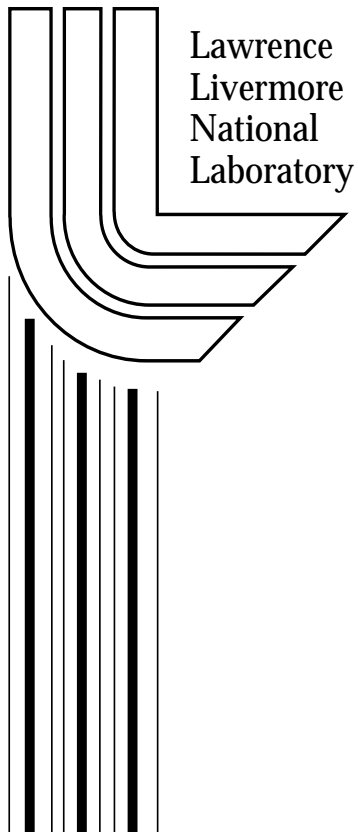

November 26, 2002 


\section{DISCLAIMER}

This document was prepared as an account of work sponsored by an agency of the United States Government. Neither the United States Government nor the University of California nor any of their employees, makes any warranty, express or implied, or assumes any legal liability or responsibility for the accuracy, completeness, or usefulness of any information, apparatus, product, or process disclosed, or represents that its use would not infringe privately owned rights. Reference herein to any specific commercial product, process, or service by trade name, trademark, manufacturer, or otherwise, does not necessarily constitute or imply its endorsement, recommendation, or favoring by the United States Government or the University of California. The views and opinions of authors expressed herein do not necessarily state or reflect those of the United States Government or the University of California, and shall not be used for advertising or product endorsement purposes.

This is a preprint of a paper intended for publication in a journal or proceedings. Since changes may be made before publication, this preprint is made available with the understanding that it will not be cited or reproduced without the permission of the author 


\title{
Influence of BK7 substrate solarization on the performance of hafnia and silica multilayer mirrors
}

\author{
C. J. Stolz, J. A. Menapace, F. Y. Génin, P. R. Ehrmann, P. E. Miller, and G. T. Rogowski \\ University of California, Lawrence Livermore National Laboratory \\ P. O. Box 808, L-491, Livermore, CA 94550
}

\begin{abstract}
Transport mirrors within the National Ignition Facility, a 192-beam 4-MJ fusion laser at $1053 \mathrm{~nm}$, will be exposed to backscattered light from plasmas created from fusion targets and backlighters. This backscattered light covers the UV and visible spectrum from $351-600 \mathrm{~nm}$. The transport mirror BK7 substrates will be intentionally solarized to absorb $>95 \%$ of the backscattered light to prevent damage to the metallic mechanical support hardware. Solarization has minimal impact on the 351- and 1053-nm laser-induced damage threshold or the reflected wavefront of the multilayer hafnia silica coating. Radiation sources of various energies were examined for BK7 darkening efficiency within the UV and visible region with $1.1 \mathrm{MeV}$ gamma rays from a Cobalt 60 source ultimately being selected. Finally, bleaching rates were measured at elevated temperatures to generate a model for predicting the lifetime at ambient conditions $\left(20^{\circ} \mathrm{C}\right)$, before solarized BK7 substrates exceed 5\% transmission in the UV and visible region. Over a 30-mm thickness, BK7 glass will bleach in 10 years to $5 \%$ transmission at $600 \mathrm{~nm}$, the most transmissive wavelengths over the 351-600 $\mathrm{nm}$ regions.
\end{abstract}

Keywords: solarization, color center, BK7 glass, mirrors, hafnia/silica multilayers, gamma irradiation, bleaching kinetics

\section{INTRODUCTION}

The primary function of the transport mirror coatings on the National Ignition Facility (NIF) is to steer the 1053-nm laser radiation from the amplifiers to the frequency converters surrounding the target chamber. This must occur at high

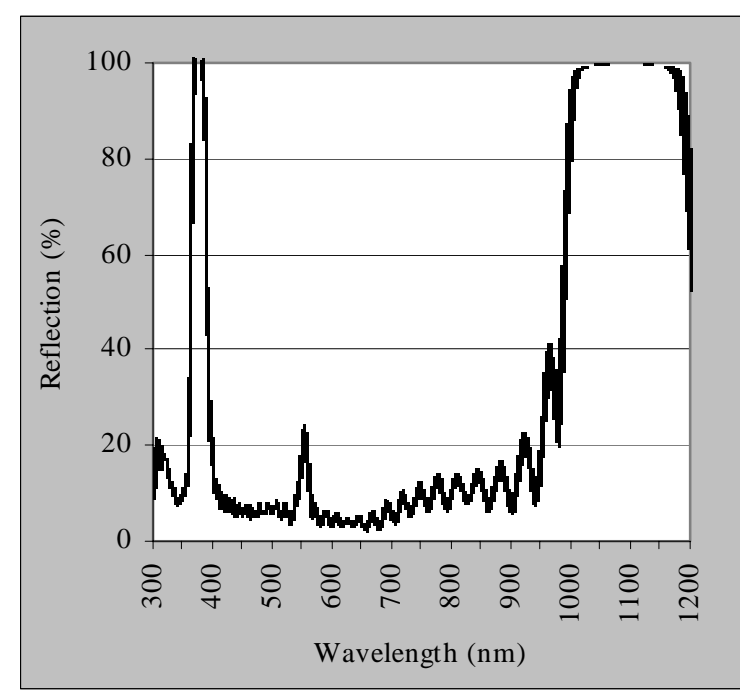

Fig. 1 Averaged spectral characteristics of 22 NIF transport mirror coating runs. The line width at each wavelength is equal to the standard deviation. fluences (up to $22 \mathrm{~J} / \mathrm{cm}^{2}$ ) with minimal losses or wavefront distortion. A secondary function of the transport mirrors is to reject light backscattered from the target $^{1}$ due to Stimulated Brillouin Scattering (SBS) from 351-353 $\mathrm{nm}$ and Stimulated Raman Scattering (SRS) from roughly $400-600 \mathrm{~nm}$. SBS and SRS must be prevented from propagating up the laser chain and damaging diagnostic instruments on NIF. This task was accomplished by selecting coating designs with both high 1053$\mathrm{nm}$ laser-damage thresholds ${ }^{2}$ and high transmission over the SBS and SRS wavelength regions. The spectral characteristics of a typical transport mirror are shown in Figure 1.

The intensity of backscattered light from the target can be as high as $2 \mathrm{~J} / \mathrm{cm}^{2}$. The majority of the energy will be transmitted through the mirror into the substrate and ultimately strike the metallic mounting hardware as illustrated in figure 2. The mirror mounting hardware consists of 3 expansion mandrels that are inserted in 50-mm deep holes cored into the substrate. The NIF transport mirrors are quite large with dimensions up to $525 \mathrm{~mm} \times$ $685 \mathrm{~mm} \times 80 \mathrm{~mm}$. To protect the mounting hardware from laser damage, radiation-induced solarization was considered as a means of inexpensively changing the absorptive characteristics of BK7 
substrates, as shown in Figure 3, to reduce the backscattered fluence to less than $100 \mathrm{~mJ} / \mathrm{cm}^{2}$ at the mounting lugs. This requires a $20 \times$ reduction in SBS and SRS transmission after propagating $30 \mathrm{~mm}$ through BK7 glass.

Radiation-induced darkening of glasses occurs when ionizing radiation generates free electrons and holes due to impurities in the glass matrix. ${ }^{3}$ These electrons can be trapped thus creating intrinsic electron and hole color centers. Typically this is an undesirable characteristic, particularly for transmissive components such as windows and lenses. Therefore, significant research has addressed color center formation in glasses which has enabled glass manufacturers to develop solarization resistant glasses by cerium doping. ${ }^{4}$ Since the composition of borosilicate glasses vary from vendor to vendor, the spectrum of radiation darkening has been explored for the different glass suppliers of NIF mirrors.

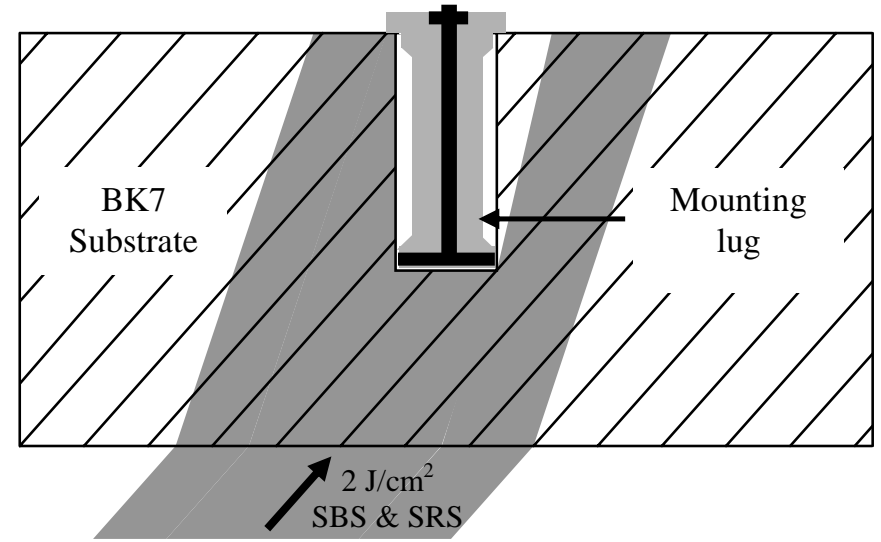

Fig. 2 Cross-sectional area of a mounting lug inside a NIF transport mirror. Backscattered light (SBS \& SRS) could damage the lug if not absorbed by the solarized BK7.

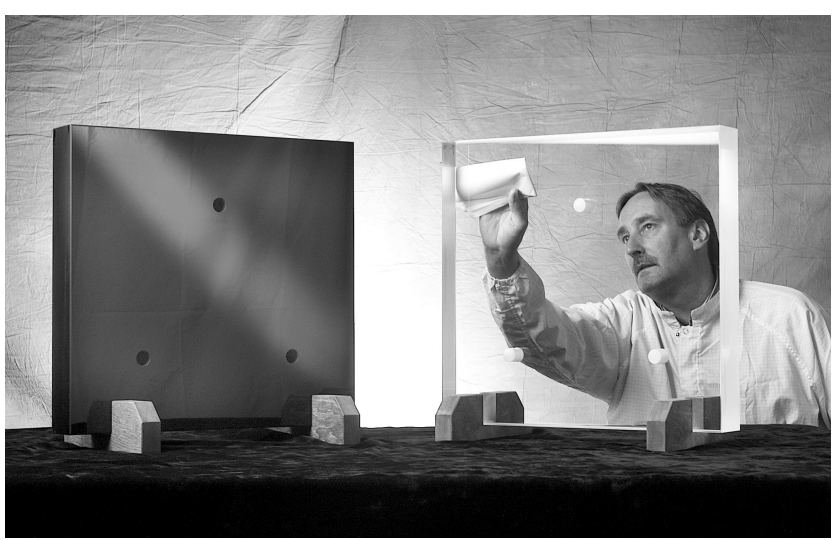

Fig. 3 Solarization turns clear BK7 into absorbing glass to protect the mounting lugs from SBS \& SRS backscatter. Note the three mounting holes in each mirror.

\section{RADIATION SOURCE ENERGY}

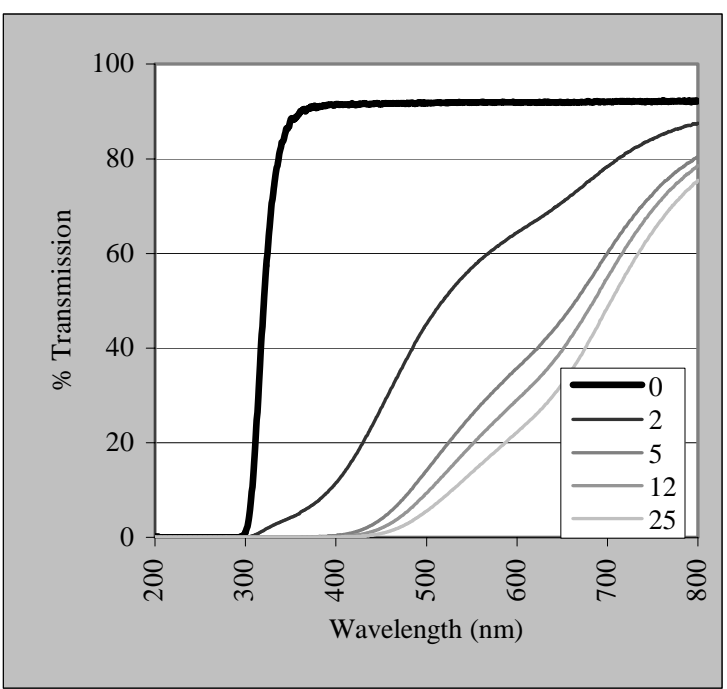

Fig.4 Spectrum of solarized BK7 exposed to $50 \mathrm{KeV}$ $\mathrm{X}$-rays as a function of wavelength and radiation exposure duration (in minutes).
To understand the minimum radiation required to reduce the transmission by greater than 20 times at $600 \mathrm{~nm}$, uncoated BK7 glass substrates were exposed to different $\mathrm{x}$-ray radiation energies ranging from $50-450 \mathrm{KeV}$. A BK7 sample (50-mm diameter $\times 10-\mathrm{mm}$ thick) manufactured by Schott was irradiated at LLNL with a Rh anode $\mathrm{x}$-ray tube operated at $50 \mathrm{KeV}$, and an emission current of $60 \mathrm{~mA}$. The optical transmission of the BK7 sample was measured before and after irradiation using a UVvisible spectrometer (Shimadzu, model UV-1601 PC). The transmission at $351 \mathrm{~nm}$ (SBS) drops below 5\% with less than 5 minutes of exposure as illustrated in Figure 4. As the exposure time increases, the transmission decreases. However, the magnitude of change in transmission decreases with increased exposure indicating a saturation effect. Even though the radiation darkening penetrated the entire sample thickness of $13 \mathrm{~mm}$, the solarization was significantly darker at the front surface than the exit surface. Visually, the estimated thickness where the intensity of the absorption drops to $1 / \mathrm{e}$ is $5 \mathrm{~mm}$.

The efficiency of darkening is also reduced as the wavelength increases. The highest wavelength in the SRS spectra is $600 \mathrm{~nm}$. The transmission of the uncoated solarized substrate at $600 \mathrm{~nm}$, 
including Fresnel losses, is $22 \%$. Based on these measurements and the saturation effect, it is obvious that higher energy sources are necessary to achieve adequate darkening penetration for simultaneous blocking of both SBS and SRS backscatter.

Further tests with higher energy x-rays were conducted at LLNL using 150, 300, and $450 \mathrm{KeV}$ gamma ray energy. An 80-mm thick Schott BK7 substrate that matches the NIF transport mirror thickness was used because greater darkening penetration was expected. 50-mm diameter collimated x-ray beams were used to create the solarized spots shown in Figure 5. After 3 hours, it became apparent that insufficient darkening occurs at $150 \mathrm{KeV}$. However, at both 300 and $450 \mathrm{KeV}$, there is less than $5 \%$ transmission at $600 \mathrm{~nm}$. The majority of the darkening occurs within $30 \mathrm{~mm}$ from the irradiated surface. The $300 \mathrm{KeV}$ exposed site appears darker than the $450 \mathrm{KeV}$ site due to the longer duration of $\mathrm{x}$-ray exposure.
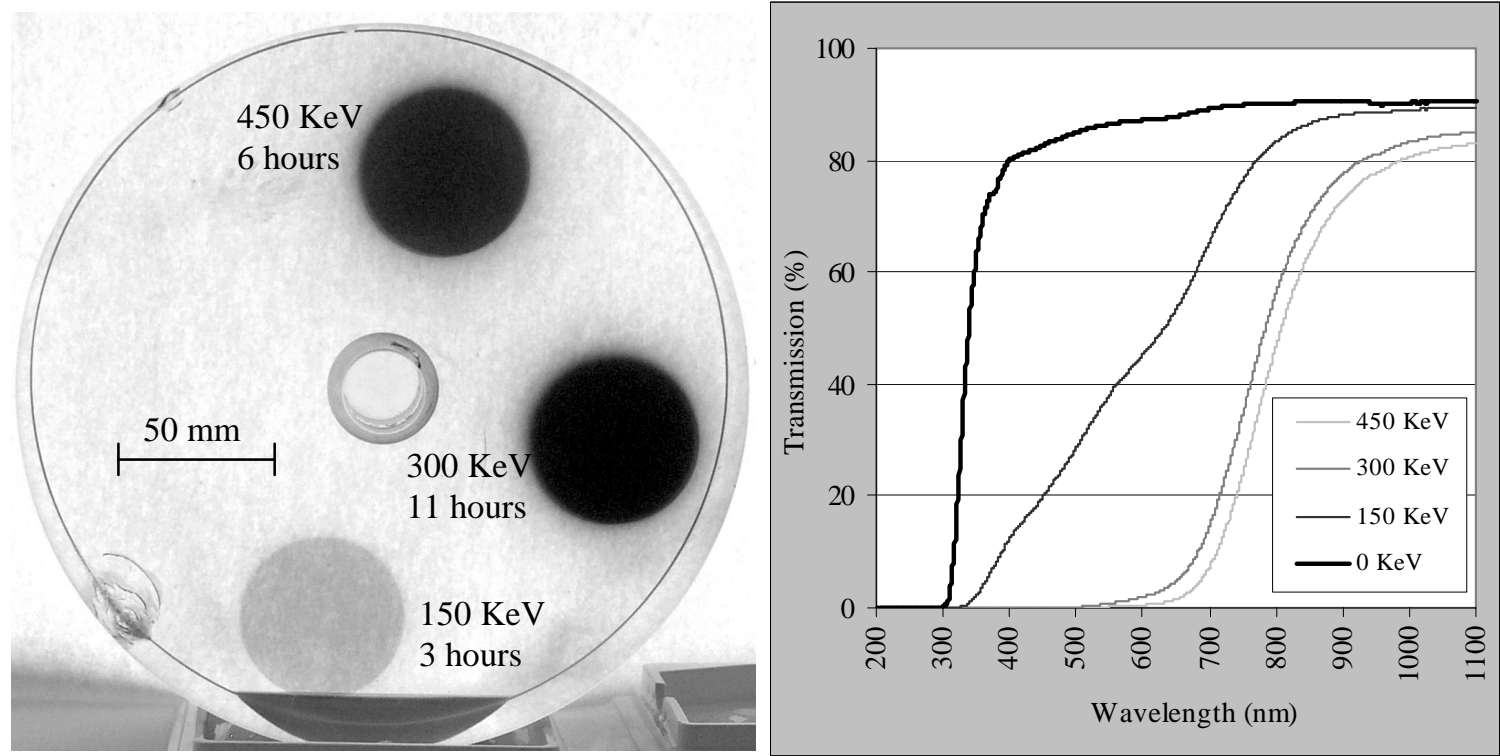

Fig. 5 Image of 80-mm thick BK7 exposed to 50-mm diameter $\mathrm{x}$-ray at 150, 300, and $450 \mathrm{KeV}$ (left) and corresponding spectrum (right) of the solarized regions.

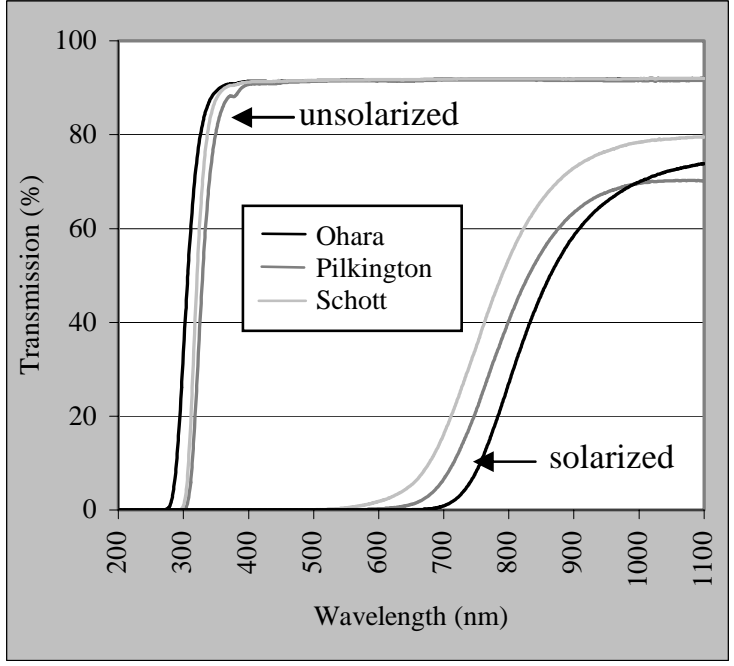

Fig. 6 Solarization spectrum of $30 \mathrm{~mm}$ thick borosilicate glasses from Schott (BK7), Pilkington (BSC517642), and Ohara (S-BSL7).
Commercial sterilization facilities with $1.1 \mathrm{MeV}$ Cobalt 60 gamma rays exist that can easily accommodate NIF-size transport mirrors at attractive prices. The penetration of 1.1 $\mathrm{MeV}$ gamma rays through borosilicate glasses is $80 \mathrm{~mm}$ at $1 / \mathrm{e}$. To understand the uniformity of darkening through an 80$\mathrm{mm}$ thick BK7 substrate, $10-\mathrm{mm}$ samples were stacked together to reach a total thickness of nearly $80 \mathrm{~mm}$. The non-uniformity of the absorption coefficient in the UV and visible spectrum was no worse than $13 \%$ and is given by the equation:

$$
\alpha=\frac{-\ln \left(T_{\text {solarized }} / T_{\text {unsolarized }}\right)}{d}
$$

NIF transport mirrors are supplied by several material vendors. Therefore, the solarization efficiency of the different materials becomes significant. Three different glasses; Schott BK7, Ohara S-BSL7, and Pilkington BSC517642 were exposed to 25 kGray of $1.1 \mathrm{MeV}$ Cobalt 60 gamma radiation. Slight differences in glass composition lead to the differences in solarization efficiency as illustrated in Figure 6. These curves are based on measured optics that are only 10-mm thick. In 
order to meet the $5 \%$ transmission requirement at $600 \mathrm{~nm}$ over $30 \mathrm{~mm}$ thickness, a transmission of roughly $37 \%$ is needed for a $10-\mathrm{mm}$ thick witness.

Ultimately the solarization needs to occur in coated optics, therefore it is important to understand when to solarize the optic during the mirror manufacturing process. Solarizing before deposition will change the thermal absorption characteristics of the substrate thus potentially impacting both coating stress and absorption. Solarizing after coating could also impact coating stress and laser damage threshold. What ultimately determines the appropriate time to solarize the optic in the manufacturing process is the rate at which the optic bleaches at elevated temperatures. At coating deposition temperatures $\left(\sim 200^{\circ} \mathrm{C}\right)$ and typical thermal cycles (24 hours), the magnitude of bleaching is quite pronounced as shown in Figure 7. A more in-depth treatment of this phenomenon is covered in section 5 where thermal annealing is used as an accelerated test to predict bleaching at ambient conditions.

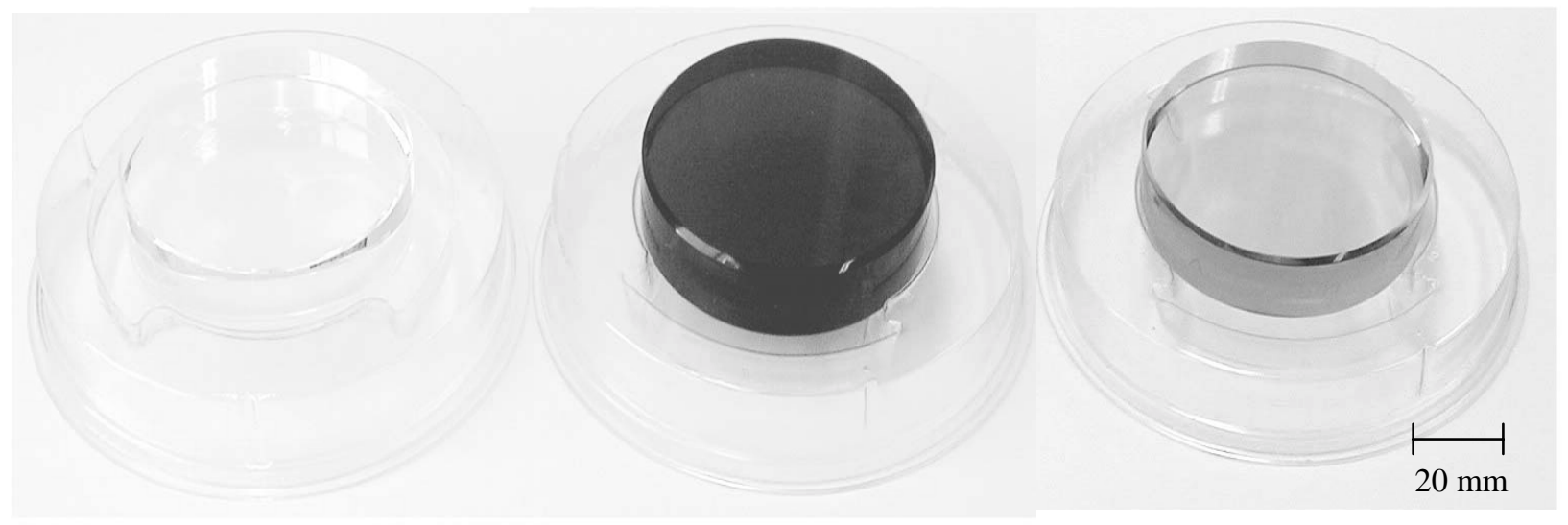

Fig. 7 Impact of $1.1 \mathrm{MeV}$ gamma rays on BK7. Left image is an unexposed optic. Central image is an optic exposed to $25 \mathrm{kGray}$. Right image is the same optic, but bleached during exposure to elevated temperatures $\left(200^{\circ} \mathrm{C}\right)$ typical of e-beam deposition.

\section{LASER DAMAGE THRESHOLD}

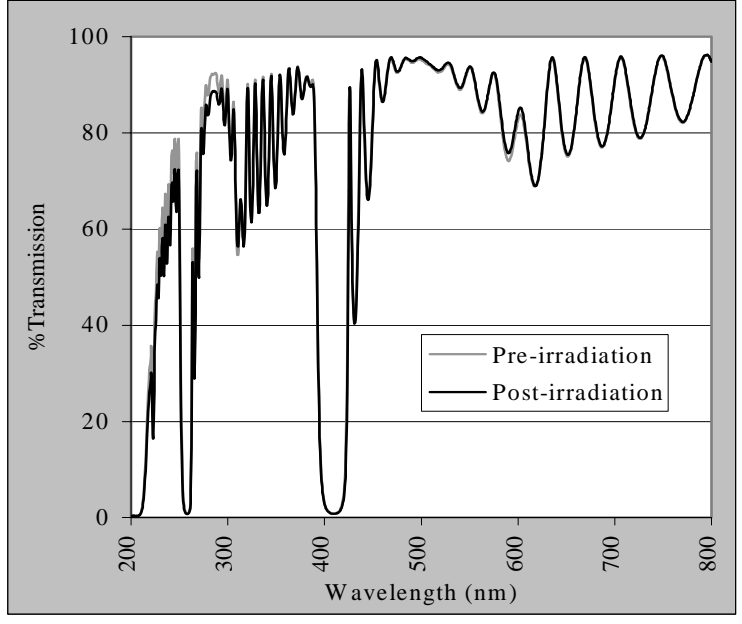

Fig. 8 Spectrum of a transport mirror coating on fused silica exposed to $2.8 \mathrm{Mrad}$ of $50 \mathrm{KeV}$ x-rays.
Although the impact of solarization on interface absorption has been studied ${ }^{5}$, the impact of solarization on the damage threshold of dielectric mirror coatings was unknown. A fused silica sample (50-mm diameter x 10-mm thick) manufactured by Corning (7980) was coated with a 45 degree hafnia silica mulitilayer transport mirror coating and irradiated by $\mathrm{x}$-rays. Fused silica does not easily solarize providing us the opportunity to explore the effects of irradiation on the coating alone.

The fused silica optic was irradiated from the coated side for a duration of 9 minutes. All irradiation was conducted with a Rh anode $\mathrm{x}$-ray tube operated at $50 \mathrm{KeV}$, and an emission current of $60 \mathrm{~mA}$. Under these conditions the dose is roughly $520 \mathrm{rad} / \mathrm{sec}$, so the coated side was exposed to a dose of about 2.8 Mrad. Figure 8 illustrates the small impact of $x$-ray irradiation on the UV transmission of the optical properties of the coated fused silica optic as measured before and after irradiation. The visible and IR regions show negligible changes. Although this result is promising, the critical parameter is the 1- and 3- $\omega$ damage threshold which must not be degraded given the high fluence requirements of the NIF transport mirrors. 
Damage tests were also conducted on the x-ray exposed coated fused silica optic in an attempt to differentiate between irradiation-induced substrate absorption effects and potential modification of coating defects. The damage test was compared to a control sample coated on BK7 in the same transport mirror run. A raster-scan damage test was conducted at a wavelength of $1064 \mathrm{~nm}$ and pulse length of $10 \mathrm{~ns}$. The damage threshold is defined as the fluence at which $50 \mu \mathrm{m}$ or larger size damage is first detected. The irradiated and control sample were both examined after each scan for damage to determine the damage threshold. The fluences used in the tests were $9.8,13.8,18,22.1$, and $25.9 \mathrm{~J} / \mathrm{cm}^{2}$ scaled from $10 \mathrm{~ns}$ to $3 \mathrm{~ns}$ using $\tau=0.35$ for the $\mathrm{x}$-ray exposed sample and 18,20 , and $24.7 \mathrm{~J} / \mathrm{cm}^{2}$ for the control sample. The reported damage thresholds are $22.4 \mathrm{~J} / \mathrm{cm}^{2}$ and $24 \mathrm{~J} / \mathrm{cm}^{2}$ for the control and $\mathrm{x}$-ray exposed samples respectively. The difference of $10 \%$ is considered insignificant compared to a damage testing measurement error of $15 \%$.

A full-aperture mirror was also damage tested before and after solarization since small-aperture damage tests are not always representative of large-aperture damage thresholds. The optic was raster scanned over $25 \%$ of the area as described elsewhere ${ }^{6}$ at fluences of $10,14,18,20,22$, and $25 \mathrm{~J} / \mathrm{cm}^{2}$. The damage threshold is defined as the fluence at which $300 \mu \mathrm{m}$ or larger size damage is first detected. Damage was observed at $25 \mathrm{~J} / \mathrm{cm}^{2}$, which is typical of NIF transport mirrors. ${ }^{2}$ The optic was then solarized and damage tested over another $25 \%$ area that was previously untested. Again the damage threshold was $25 \mathrm{~J} / \mathrm{cm}^{2}$, however, a high density, 1 per $\mathrm{cm}^{2}$, of plasma scalds ${ }^{7}$ were observed compared to less than 0.003 scalds per $\mathrm{cm}^{2}$ in the unsolarized test. Although plasma scalds have been determined to be a benign damage morphology ${ }^{8}$, a subsequent experiment was designed to determine if plasma scalding could be reduced.

A second mirror was coated to explore whether the plasma scalding density could be reduced to unsolarized densities. After coating, the mirror was processed like all NIF transport mirrors. It was laser conditioned with 3 fluence steps; 10 , 14 , and $18 \mathrm{~J} / \mathrm{cm}^{2}$. Previous experiments have validated that laser conditioning improves the damage threshold of electron beam coatings by 2 times. $^{6}$ The mirror was then solarized and rescanned at $18 \mathrm{~J} / \mathrm{cm}^{2}$. No significant change was observed in the plasma scald density after solarization and raster scanning.

Damage tests were also conducted on a 50-mm diameter coating witness at $3 \omega$. Solarized substrates and coatings have little absorption at $1 \omega$, therefore it is reasonable to expect little differences in the laser damage threshold at $1 \omega$. The impact on $3 \omega$ damage threshold is less certain due to the high substrate absorption and small transmission differences in

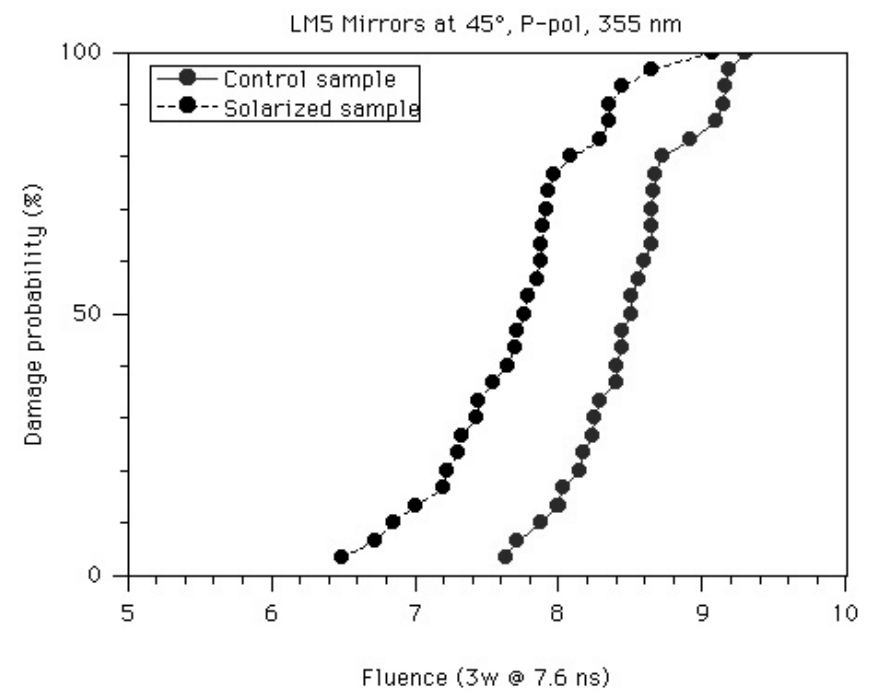

Fig. 9 Damage threshold probability curve at $351 \mathrm{~nm}$ of transport mirror coating before and after solarization. a coating after solarization. Typically $3 \omega$ damage is much more intrinsic in nature enabling standard $\mathrm{S}: 1$ and R:1 testing. Specifically, either the entire irradiated area becomes damaged (high density of pinpoint scatter sites) or no damage occurs. This is very different than the lowdensity damage that occurs at $1 \omega$ leading to the significant difference in damage threshold with area tested. The 50-mm diameter coating witness was damage tested using the R:1 method. An area of $1 \mathrm{~cm}^{2}$ was tested before and after solarization with the results illustrated in figure 9. The damage threshold is defined as the fluence at which $10-\mu \mathrm{m}$ or larger size damage is first detected. The NIF requirement is a $3 \omega$ damage threshold of $2 \mathrm{~J} / \mathrm{cm}^{2}$ compared to the $\mathrm{R}: 1$ measured values of 7.6 and $6.4 \mathrm{~J} / \mathrm{cm}^{2}$ before and after solarization respectively. Finally, the unconditioned $\mathrm{S}: 1$ damage threshold was measured at $3 \omega$ over a $1 \mathrm{~cm}^{2}$ area. Damage occurred at $3.0 \mathrm{~J} / \mathrm{cm}^{2}$ and $2.5 \mathrm{~J} / \mathrm{cm}^{2}$ before and after solarization, respectively. A summary of these results are listed in table 1. 
Table 1 Summary of testing results suggest solarization has a negligible impact on laser damage threshold

\begin{tabular}{|c|c|c|c|c|c|}
\hline $\begin{array}{l}\text { Wavelength } \\
\text { (in nm) }\end{array}$ & Test type & $\begin{array}{l}\text { Test area } \\
\left(\text { in } \mathrm{cm}^{2}\right)\end{array}$ & $\begin{array}{l}\text { Damage size criteria } \\
\text { (in } \mu \mathrm{m} \text { ) }\end{array}$ & Solarized & $\begin{array}{l}\text { Damage threshold } \\
\text { (in } \mathrm{J} / \mathrm{cm}^{2} \text { at } 3 \mathrm{~ns} \text { ) }\end{array}$ \\
\hline \multirow[t]{4}{*}{1053} & \multirow[t]{4}{*}{ Raster scan } & \multirow[t]{2}{*}{1} & \multirow[t]{2}{*}{50} & No & 24.7 \\
\hline & & & & Yes & 22.4 \\
\hline & & \multirow[t]{2}{*}{582} & \multirow[t]{2}{*}{300} & No & 25 \\
\hline & & & & Yes & 25 \\
\hline \multirow[t]{4}{*}{351} & \multirow[t]{2}{*}{$\mathrm{S}: 1$} & \multirow[t]{4}{*}{1} & \multirow[t]{4}{*}{10} & No & 2.5 \\
\hline & & & & Yes & 3 \\
\hline & \multirow[t]{2}{*}{$\mathrm{R}: 1$} & & & No & 7.6 \\
\hline & & & & Yes & 6.4 \\
\hline
\end{tabular}

\section{REFLECTED WAVEFRONT}

A high resolution (0.43-mm pixel size) 24" WYKO phase-measuring interferometer with a wavelength of $668 \mathrm{~nm}$ was used to measure the reflected wavefront of a coated NIF transport mirror before and after solarization. The reflected wavefront is directly proportional to the surface figure and coating stress. The mirror was measured at use angle, but outside of the reflection band of the coating which can lead to phase-induced errors due to minor coating thickness variations ( $<1 \%$ nonuniformity) across the coated optic. Therefore, only a comparison of the difference in the reflected wavefront of the mirror before and after solarization is valid. The stress of electron-beam deposited coatings is sensitive to humidity ${ }^{9}$ so the relative humidity was at ambient conditions where the coating stress is least sensitive. The relative humidity differed by less than 5\% between measurements. The P-V and RMS gradient, as illustrated in Figure 10, changed by 0.055 waves and by 0.001 waves $/ \mathrm{cm}$ respectively at the use wavelength of NIF $(1053 \mathrm{~nm})$. These changes are within experimental error thus are considered insignificant.

The reflected wavefront of the mirror can also be impacted by the amount of heating that occurs when the SBS and SRS light is absorbed within the substrate. To better understand this issue, a finite element model was constructed using TOPAZ to calculate the thermal transients. These data were then used as the input of an identical finite element model in NIKE, a thermal code used to calculate the distortion.

The desired thermal recovery rate for NIF is not to exceed 4 hours. Currently the amplifier slabs limit the thermal recovery time on NIF. All other components are required to have thermal recovery times less than the amplifier slabs. The thermal calculations were done assuming $2 \mathrm{~J} / \mathrm{cm}^{2}$ incident energy. The mirror radiates and convects into Argon gas at ambient temperature $\left(20^{\circ} \mathrm{C}\right)$. Conduction occurs through the mounting lugs into the rest of the mechanical structure. At $2 \mathrm{~J} / \mathrm{cm}^{2}$ the anticipated P-V normal displacement is $4.5 \mathrm{~nm}$ or 0.009 waves reflected wavefront at $1053 \mathrm{~nm}$ as illustrated in Figure 11.
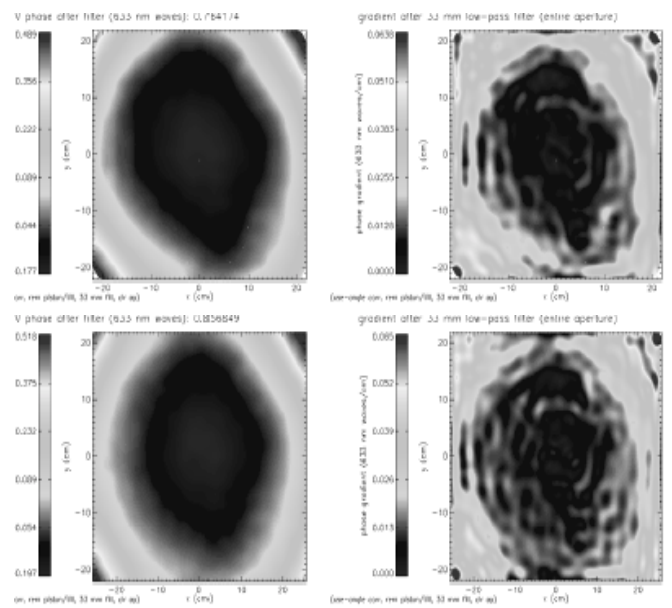

Fig. 10 Wavefront results of p-v (left) and RMS gradient (right) of before (top) and after (bottom) solarization. The $\mathrm{p}-\mathrm{v}$ changed 0.055 waves and the RMS gradient changed 0.001 waves $/ \mathrm{cm}$.

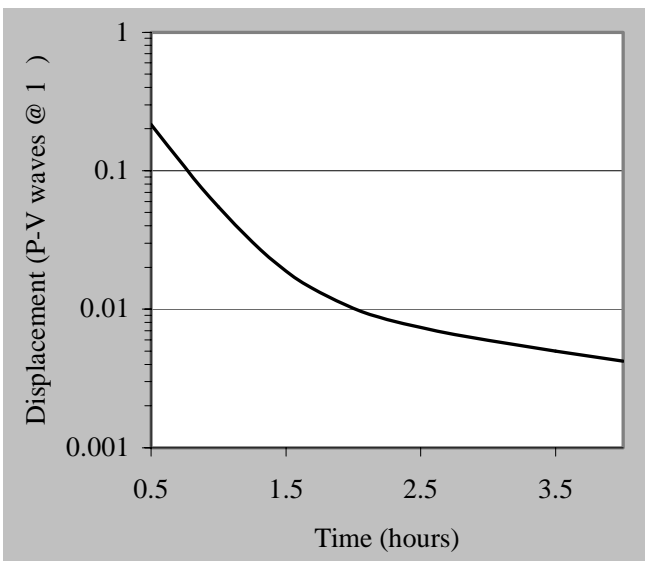

Fig. 11 The modeled surface figure distortion of a transport mirror is $4.5 \mathrm{~nm}$ after 4 hours. The distortion is caused by thermal effects when SBS and SRS is absorbed in the solarized mirror. 


\section{BLEACHING RATES}

Color centers can be annihilated by releasing the trapped electrons thus holes and allowing them to recombine. ${ }^{10}$ This process is accelerated at elevated temperature as illustrated in Figure 12. Because of this, optics can not be solarized prior to electron beam coating since such coatings are applied at elevated temperatures $\left(\sim 200^{\circ} \mathrm{C}\right)$.

Although the bleaching rate slows at lower temperatures, it is not negligible at ambient temperatures. To predict the lifetime of NIF transport mirrors maintaining a $600-\mathrm{nm}$ transmission of less that $5 \%$ over $30-\mathrm{mm}$ distance, a model consisting of a basis set of two branched second-order reactions was constructed.

\subsection{Bleaching measurements}

A convection oven containing two 2-kg copper $(\mathrm{Cu})$ blocks was used for the BK7 bleaching trials. Prior to the bleaching tests, the $\mathrm{Cu}$ blocks were allowed to thermally equilibrate in the oven at the desired experimental temperature. Following equilibration, the solarized optic was quickly placed in the oven between the two $\mathrm{Cu}$ blocks. The temperature drop of the $\mathrm{Cu}$ blocks ranged from about $1^{\circ} \mathrm{C}$ at the low temperature bleaching trial up to about $3^{\circ} \mathrm{C}$ at the high temperature trial. Following the desired incubation period, the optic was removed and placed between two room temperature $\mathrm{Cu}$ blocks. Transmission measurements were taken on the optic following cooling.

Optical transmission measurements were taken from $1100 \mathrm{~nm}$ to $200 \mathrm{~nm}$ using a commercial UV-visible spectrometer. Sample surfaces were carefully cleaned with ethanol and lens tissue prior to taking optical measurements. Duplicate transmission measurements were taken and averaged. The absorption band at $525 \mathrm{~nm}$ was used to track the rate of bleaching in each BK7 optic.

\subsection{Bleaching model}

In order to determine an adequate predictive bleaching model, absorption was determined as a function of thermal annealing time and temperature. As illustrated in Figure 13, the bleaching rate quickly drops with time at constant temperature. Also, low temperatures were found to be dominated by one reaction rate while high temperatures had a very different reaction rate. Given the dichotomy of these results, a model with two branching second-order reactions was constructed.
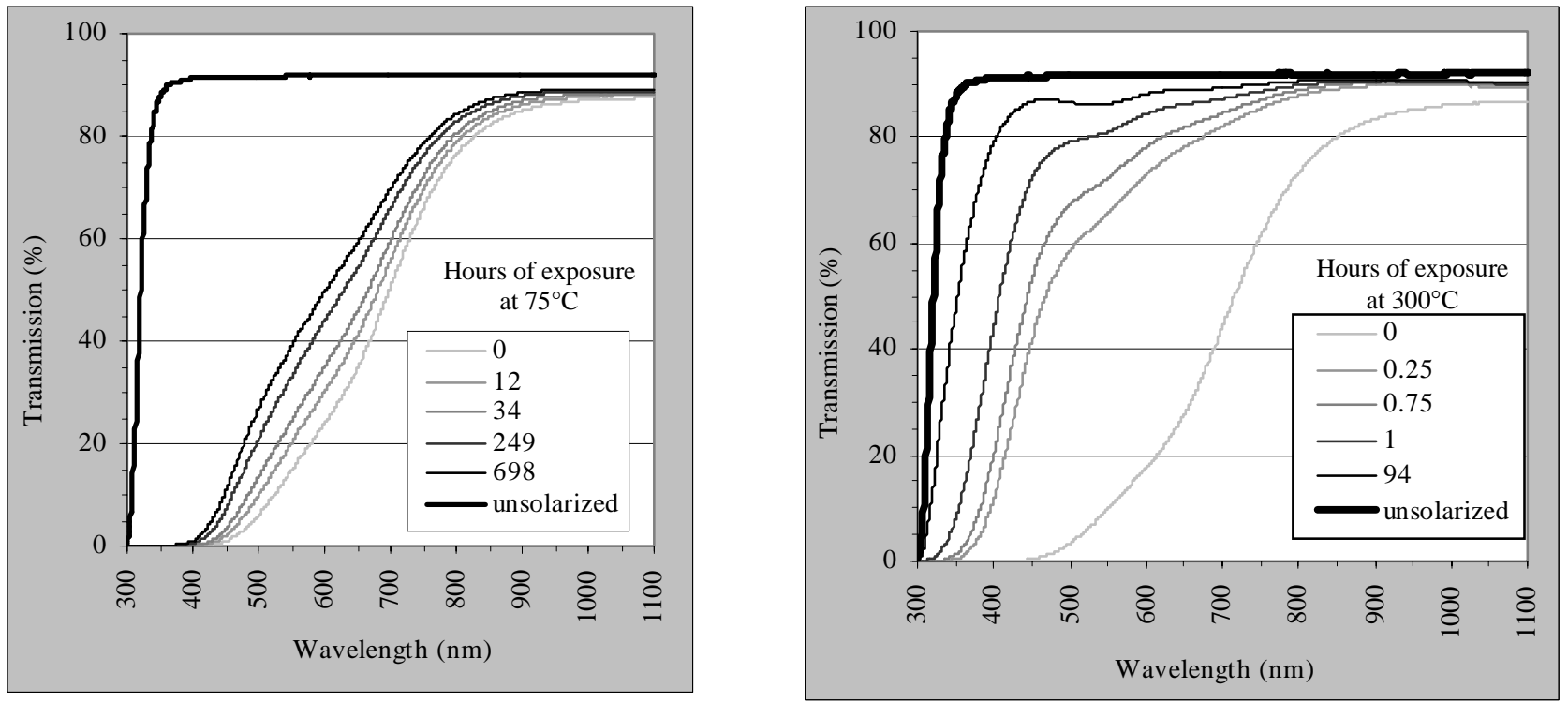

Fig. 12 Spectrums of solarized BK7 after different thermal exposure times (left image $75^{\circ} \mathrm{C}$; right image $300^{\circ} \mathrm{C}$ ). 

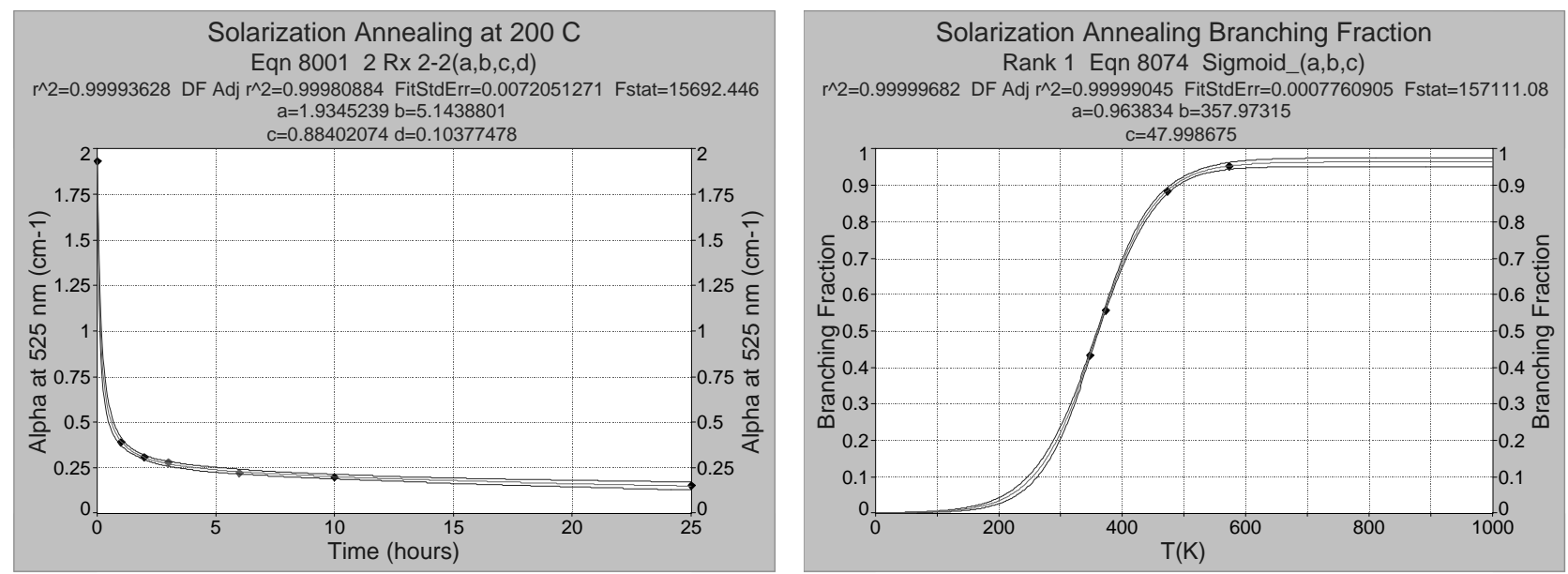

Fig. 13 Bleaching rate at constant temperature decreases with time (left graph). Branching fraction is the contribution of each of the low and high temperature reaction types considered over a range of temperatures (right graph).

The equation used to mold the thermal annealing is as follows:

$$
\alpha(t)=\alpha_{o}\left(\frac{\beta}{1+\beta \alpha_{o} K_{1} t}+\frac{1-\beta}{1+(1-\beta) \alpha_{o} K_{2} t}\right)
$$

where $\alpha$ is the wavelength and time dependent absorption coefficient (Figure 13), $\beta$ is the branching fraction of the low and high temperature reactions (Figure 13), and the rate constants are $\mathrm{K}_{\mathrm{i}}=\mathrm{Ae}$-Ea/RT (Figure 14). All of these parameters were determined by fitting the experimental data collected at each temperature to the model for each of the 3 different borosilicate glasses. Excellent agreement between theoretical predictions and experimental results was observed as illustrated in Figure 14.
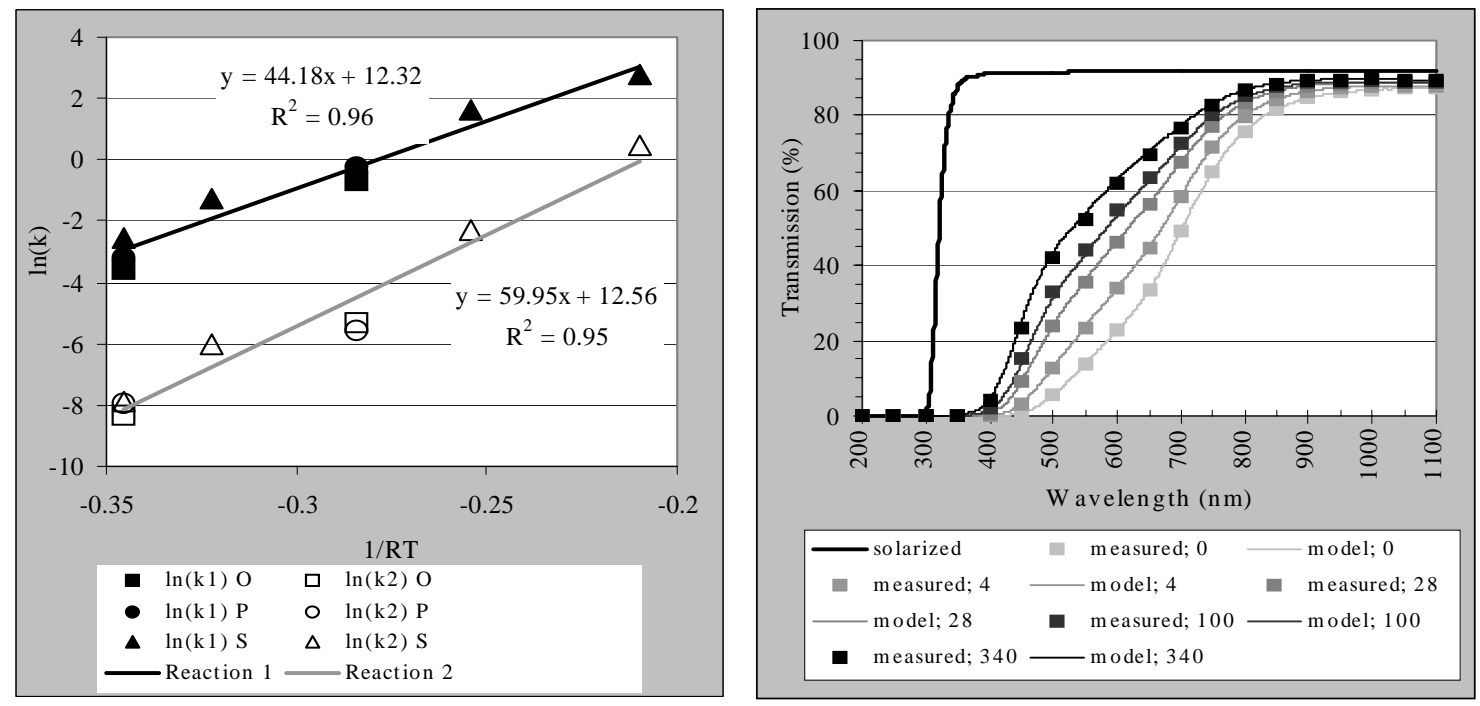

Fig. 14 Arrhenius plot of temperature dependence of rate constants of borosilicate glasses from Ohara (O), Pilkington (P), and Schott (S) for the two different reactions (left chart). Comparison of theory and experiment of bleaching rates at different time durations (in minutes) at $200^{\circ} \mathrm{C}$ (right image). 
Using the model, bleaching rates can be extrapolated to $20^{\circ} \mathrm{C}$ for each of the three different glasses as illustrated in Figure 15. Low temperature bleaching studies are underway to validate the extrapolation, however, a year or two will be required between tests to get any meaningful data. According to the model, the lifetime of a NIF transport mirror before the transmission at $600 \mathrm{~nm}$ increases to $5 \%$ is 10 years for all three glass types. After 10 years, the mirrors will need to be removed from NIF, resolarized, and reinstalled. The expected replacement rate of transport mirrors due to laser damage during operations is approximately $10 \%$ so about half of the final transport mirrors will be replaced before resolarization is necessary.

BK7 also solarizes when exposed to $3 \omega$ (SBS) laser light. This will tend to slow the bleaching rate or reverse its effects. Given the range of different experiments on NIF resulting in a wide range of SBS fluences, it is difficult to anticipate the significance of SBS induced solarization. During transport mirror refurbishment, laser-damaged mirrors will be measured to refine the lifetime model to include the presence of SBS light.
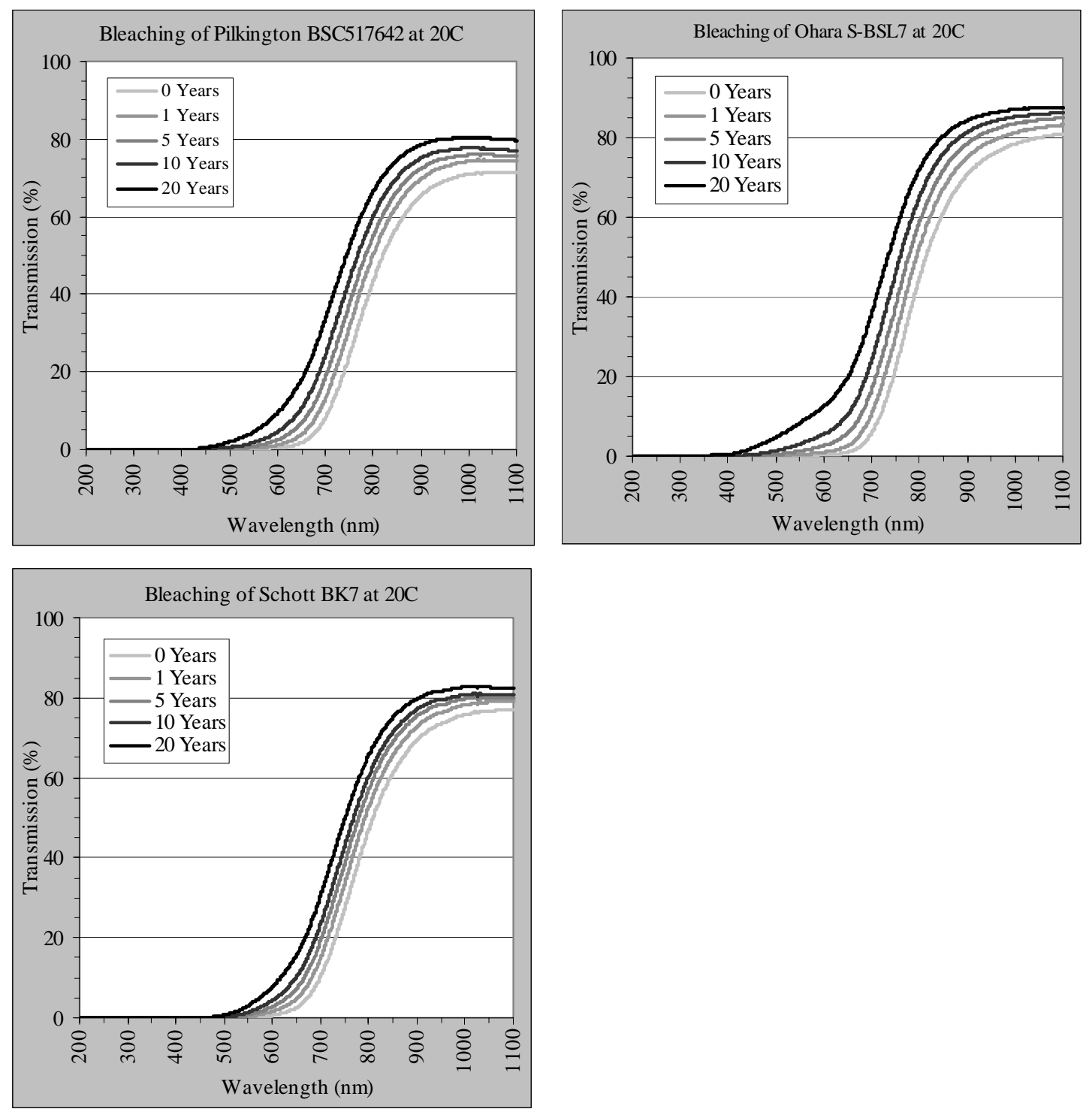

Fig. 15 Modeled bleaching rates at $20^{\circ} \mathrm{C}$ of $3-\mathrm{cm}$ thick common borosilicate glasses from 3 different glass vendors. 


\section{CONCLUSIONS}

Solarization is an effective low-cost method of increasing the blocking efficiency at UV and visible wavelengths. Solarization also has minimal impacts on the laser damage threshold at both 1-and 3- $\omega$. The reflected wavefront of solarized mirrors is also not significantly altered. The solarization effect is reversible and the effect is accelerated as temperature of the substrate is increased. A model was constructed based on accelerated testing at elevated temperature to predict a 10 year lifetime for solarized mirrors before the transmission at $600 \mathrm{~nm}$ will increase to $5 \%$.

\section{ACKNOLEDGEMENTS}

The authors would like to acknowledge the support of Andrea Flammini in preparing this manuscript and Mark McDaniel for assistance with the graphics. The authors would also like to acknowledge the gamma x-ray exposure testing of Jeff Gross and Jerry Haskins at LLNL. Gamma ray tests were conducted at Steris, Inc. and IBA. Thermal calculations were performed by Wayne Miller and interferometry measurements by Will House. Damage tests were performed by Mike Runkle at LLNL and Jason Tanaguchi at LLE. This work was performed under the auspices of the U. S. Department of Energy by the University of California, Lawrence Livermore National Laboratory under Contract No. W-7405-Eng-48.

\section{REFERENCES}

1. S. H. Glenzer, L. J. Suter, R. L. Berger, K. G. Estabrook, B. A. Hammel, R. L. Kauffman, R. K. Kirkwood, B. J. MacGowan, J. D. Moody, J. E. Rothenberg, and R. E. Turner, "Hohlraum energetics with smoothed laser beams" Phys. of Plasmas 7, 2585-2593 (2000).

2. J. Taniguchi, N. E. LeBarron, J. Howe, D. J. Smith, C. J. Stolz, C. L. Weinzapfel, and J. F. Kimmons, "Functional damage thresholds of hafnia/silica coating designs for the NIF laser", in Laser-Induced Damage in Optical Materials: 2000, G. J. Exarhos, A. H. Guenther, M. R. Kozlowski, K. L. Lewis, and M. J. Soileau, eds., SPIE 4347, 109-117 (2001).

3. H. A. Papazian, "Color center defects: an alternative view," Solid State Ionics 38, 5-8 (1990).

4. J. S. Stroud, "Color centers in a Cerium-containing silicate glass," J. Chem. Phys. 37, 836-841 (1962).

5. L. Escoubas, A. Gatto, G. Albrand, P. Roche, and M. Commandré, "Solarization of glass substrates during thin-film deposition," Appl. Opt. 37, 1883-1889 (1998).

6. C. J. Stolz, L. M. Sheehan, S. M. Maricle, S. Schwartz, and J. Hue, "A study of laser conditioning methods of hafnia silica multiplayer mirrors," in Laser-Induced Damage in Optical Materials: 1998, G. J. Exarhos, A. H. Guenther, M. R. Kozlowski, K. L. Lewis, and M. J. Soileau, eds., SPIE 3578, 144-152 (1999).

7. F. Y. Génin and C. J. Stolz, "Morphologies on laser-induced damage in hafnia-silica multiplayer mirror and polarizer coatings," in Third International Workshop on Laser Beam and Optics Characterization, M. Morin and A. Giesen, eds., SPIE 2870, 439-448 (1996).

8. F. Y. Génin, C. J. Stolz, and M. R. Kozlowski, "Growth of laser-induced damage during repetitive illumination of $\mathrm{HfO}_{2}-\mathrm{SiO}_{2}$ multilayer mirror and polarizer coatings," in Laser-Induced Damage in Optical Materials: 1996, H. E. Bennett, A. H. Guenther, M. R. Kozlowski, B. E. Newnam, and M. J. Soileau, eds., SPIE 2966, 273-282 (1997).

9. J. F. Anzellotti, D. J. Smith, R. J. Sczupak, and Z. R. Chrzan, "Stress and environmental shift characteristics of $\mathrm{HfO}_{2} / \mathrm{SiO}_{2}$ multilayer coatings," in Laser-Induced Damage in Optical Materials: 1996, H. E. Bennett, A. H. Guenther, M. R. Kozlowski, B. E. Newnam, and M. J. Soileau, eds., SPIE 2966, 258-264 (1997).

10. V. I. Arbuzov and F. V. Suchkov, "Stability of radiation coloration of optical glasses," J. Opt Technol. 68, 447-456 (2001). 


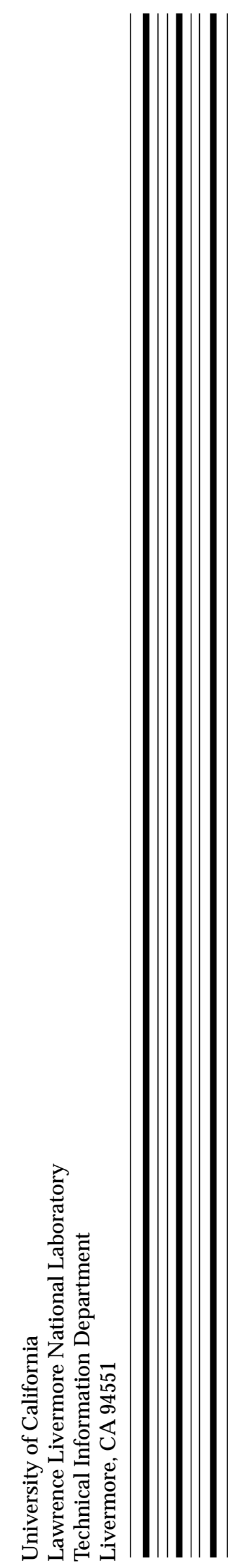

